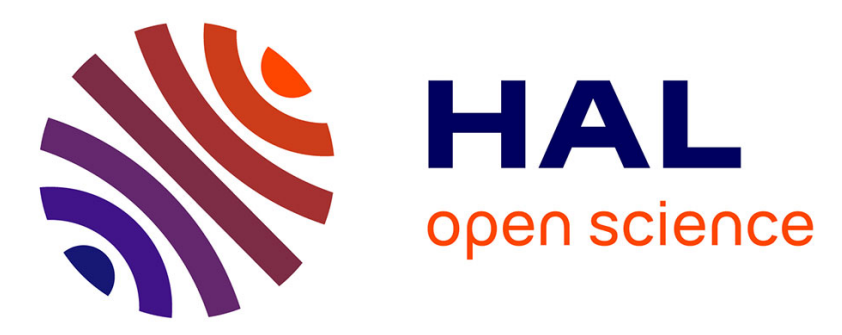

\title{
Sequential modeling of local precipitation, strength and strain hardening in friction stir welds of an aluminum alloy 6005A-T6
}

Aude Simar, Yves Bréchet, B. de Meester, A. Denquin, Thomas Pardoen

\section{- To cite this version:}

Aude Simar, Yves Bréchet, B. de Meester, A. Denquin, Thomas Pardoen. Sequential modeling of local precipitation, strength and strain hardening in friction stir welds of an aluminum alloy 6005A-T6. Acta Materialia, 2007, 55 (18), pp.6133-6143. 10.1016/j.actamat.2007.07.012 . hal-00204237

\section{HAL Id: hal-00204237 \\ https://hal.science/hal-00204237}

Submitted on 6 Feb 2018

HAL is a multi-disciplinary open access archive for the deposit and dissemination of scientific research documents, whether they are published or not. The documents may come from teaching and research institutions in France or abroad, or from public or private research centers.
L'archive ouverte pluridisciplinaire HAL, est destinée au dépôt et à la diffusion de documents scientifiques de niveau recherche, publiés ou non, émanant des établissements d'enseignement et de recherche français ou étrangers, des laboratoires publics ou privés. 


\title{
Sequential modeling of local precipitation, strength and strain hardening in friction stir welds of an aluminum alloy 6005A-T6
}

\author{
A. Simar ${ }^{a, b, *}$, Y. Bréchet ${ }^{c}$, B. de Meester ${ }^{a}$, A. Denquin ${ }^{\text {d }}$, T. Pardoen ${ }^{\text {b }}$ \\ a Département de Mécanique, Université catholique de Louvain, PRM, Place du Levant 2, B-1348 Louvain-la-Neuve, Belgium \\ ${ }^{\mathrm{b}}$ Département des Sciences des Matériaux et des Procédés, Université catholique de Louvain, IMAP, Place Sainte Barbe 2, B-1348 \\ Louvain-la-Neuve, Belgium \\ ${ }^{\mathrm{c}}$ LTPCM/INPG, CNRS UMR 5614, Domaine Universitaire, BP 75, 38402 Saint Martin d'Hères, France \\ d Office National d'Etudes et de Recherches Aérospatiales, 29 Avenue de la Division Leclerc, 92322 Châtillon Cédex, France
}

\begin{abstract}
A novel microstructure-based strain-hardening model for precipitate hardening materials is developed, accounting, in addition to the usual contributions, for the influence of a supersaturated solid solution as well as for a dependence of dynamic recovery on the yield strength and on the presence and stability of Orowan loops. This model is the third step of a chain involving: (i) a precipitation model which predicts the evolution of precipitate radius distribution and volume fraction with thermal cycles, and (ii) a model which predicts the yield strength as a function of the microstructure. The model parameters are identified from quantitative characterizations and tensile tests performed after isothermal heat treatments of AA 6005A-T6 samples. A critical assessment of the sequential three-steps model is made by predicting, based on local thermal history measurements, the local microstructures and flow properties in two friction stir welded joints generated with different advancing speeds. The predicted results show very good agreement with the local experimental data. This analysis leads to a better understanding of the competing factors controlling the strength profiles and ductility of the friction stir joints.
\end{abstract}

Keywords: Dislocation theory; Strain hardening; Ageing; Welding; Aluminium alloys

\section{Introduction}

Friction stir welding (FSW) is a relatively new welding process $[1,2]$. The plates to be welded are rigidly clamped on a machine table. A rotating FSW tool pin penetrates the material until the tool shoulder comes in contact with the upper surface of the plates. The tool moves between the faying surfaces and forms the welded joint without any melting. A FSW joint involves several zones with different microstructures and mechanical properties. One distinguishes different zones from the base material to the

\footnotetext{
* Corresponding author. Tel.: +1 510643 3281; fax: +1 5106439685.

E-mail address: aude.simar@uclouvain.be (A. Simar).
}

joint centerline (see top of Fig. 5a and b): the base material (BM), the heat affected zone (HAZ), the thermomechanically affected zone (TMAZ) and the weld nugget (WN). Both the TMAZ and the nugget are highly deformed, but only the nugget is dynamically recrystallized.

The optimization of FSW with respect to specific structural demands requires the development of predictive models to quantify the effects of the numerous process and materials parameters affecting the joint properties. There is thus an obvious need for an integrated modeling approach which encompasses the thermal analysis, microstructural evolution, local flow properties prediction and global properties simulation (accounting for possible post-welding heat treatments). The main missing ingredient 
for success in this integrated modeling approach is the current limited potential of microstructure-based mechanical models to predict the strain-hardening capacity of agehardenable Al alloys. Indeed, proper estimation of the variations in the strain-hardening capacity is essential for capturing both the resistance to plastic deformation localization and the joint strength which, in turn, control formability and fracture toughness. Hence, the focal point of the paper is to build a physically based model for both yield stress and work hardening behavior in relation to the precipitation state. This model is then coupled with a microstructure evolution model and applied to the quantitative modeling of local properties across a FSW joint. This integrated approach is applied to the AA 6005A alloy. The motivation for selecting an alloy initially in the T6 state was to apply the model to a simple ternary alloy in a state which presents industrial interest, as it corresponds to the peak strength.

The paper is structured as follows. The integrated microstructure-based plasticity model applicable to agehardenable aluminum alloy is presented in Section 2, with an emphasis on the new strain-hardening model. Section 3 describes the material and experimental procedures, with more details about the experimental results published elsewhere $[3,4]$. Section 4 includes the results of the parameter identification, the assessment of the model on the FSW joints results and a discussion about the competing factors controlling the strength profiles in FSW joints.

\section{Integrated microstructure-based plasticity model for age- hardening $\mathrm{Al}$ alloys}

\subsection{Microstructure evolution}

The AA 6005A alloy has low copper and low excess silicon contents (see Section 3.1). The hardening phases are the metastable precursors of the stable $\mathrm{Mg}_{2} \mathrm{Si}$ phase. The precipitation sequence is the following: sss $\rightarrow$ GP zones $\rightarrow \beta^{\prime \prime} \rightarrow \beta^{\prime}\left(+\mathrm{B}^{\prime}\right) \rightarrow \beta\left(\mathrm{Mg}_{2} \mathrm{Si}\right)$. The GP zones are produced during low temperature artificial aging or natural aging at room temperature. The precipitates $\beta^{\prime \prime}$ are fully coherent needle-shaped precipitates formed in particular during the artificial aging heat treatment $\mathrm{T} 6$ and responsible for the peak hardness corresponding to the optimum size. The rod-shaped $\beta^{\prime}$ precipitates and the rectangular sectioned and elongated $\mathrm{B}^{\prime}$ precipitates are both semicoherent precipitates. The dissolution and coarsening of the fine hardening precipitates in the AA 6005A T6 base alloy is analyzed using the model developed by Myhr et al. [5-8]. For the sake of simplicity, the precipitates are assumed to be spherical, with the composition of the stable $\mathrm{Mg}_{2} \mathrm{Si}$ phase.

\subsubsection{Nucleation law}

The steady state nucleation rate $j\left(\#\left(\mathrm{~m}^{3} \mathrm{~s}\right)^{-1}\right)$ is expressed as $\left.j=j_{0} \exp -\frac{A_{0}^{3}}{(R T)^{3}\left[\ln \left(C_{\mathrm{Mg}} / C_{\mathrm{e}}\right)\right]^{2}}\right) \exp \left(-\frac{Q_{\mathrm{d}}}{R T}\right)$

where $j_{0}\left(\#\left(\mathrm{~m}^{3} \mathrm{~s}\right)^{-1}\right)$ is a material parameter, $R$ $\left(8.314 \mathrm{~J} \mathrm{~K}^{-1} \mathrm{~mol}^{-1}\right)$ is the universal gas constant, $T(\mathrm{~K})$ is the temperature, $A_{0}\left(\mathrm{~J} \mathrm{~mol}^{-1}\right)$ is a parameter related to the energy barrier for nucleation, $C_{\mathrm{Mg}}(\mathrm{wt} . \%)$ is the mean solute $\mathrm{Mg}$ content in the matrix, $Q_{\mathrm{d}}\left(\mathrm{J} \mathrm{mol}^{-1}\right)$ is the activation energy for diffusion and $C_{\mathrm{e}}(\mathrm{wt} . \%)$ is the equilibrium solute content at the precipitate/matrix interface. The dependence of $C_{\mathrm{e}}$ with temperature, i.e. the equation for the phase solvus, is given by

$C_{\mathrm{e}}=C_{\mathrm{e} 0} \exp \left(-\frac{Q_{\mathrm{e}}}{R T}\right)$

where $C_{\mathrm{e} 0}(\mathrm{wt} . \%)$ is a parameter and $Q_{\mathrm{e}}\left(\mathrm{J} \mathrm{mol}^{-1}\right)$ is the apparent solvus boundary enthalpy.

\subsubsection{Rate law}

When a precipitate of radius $r$ and $\mathrm{Mg}$ concentration $C_{\mathrm{p}}$ (wt.\%) is present within a supersaturated solid solution with a mean concentration $C_{\mathrm{Mg}}(\mathrm{wt} . \%)$, the precipitate dissolves if $C_{\mathrm{Mg}}<C_{\mathrm{i}},(r$ decreases $)$ and grows if $C_{\mathrm{Mg}}>C_{\mathrm{i}}$, where $C_{\mathrm{i}}$ is the precipitate/matrix interface concentration given by

$C_{\mathrm{i}}=C_{\mathrm{e}} \exp \left(\frac{2 \gamma V_{\mathrm{m}}}{r R T}\right)$

where $\gamma\left(\mathrm{J} \mathrm{m}^{-2}\right)$ is the precipitate/matrix interface energy and $V_{\mathrm{m}}\left(\mathrm{m}^{3} \mathrm{~mol}^{-1}\right)$ is the molar volume of the precipitate. The dissolution or coarsening rate $v\left(\mathrm{~m} \mathrm{~s}^{-1}\right)$ is

$v=\frac{\mathrm{d} r}{\mathrm{~d} t}=\frac{1}{r} \frac{C_{\mathrm{Mg}}-C_{\mathrm{i}}}{C_{\mathrm{p}}-C_{\mathrm{i}}} D_{0} \exp \left(-\frac{Q_{\mathrm{d}}}{R T}\right)$

where $D_{0}\left(\mathrm{~m}^{2} \mathrm{~s}^{-1}\right)$ is a material parameter.

In the so-called 'class model', these equations are coupled to a continuity equation for the density of precipitates of size $r$, which is solved numerically [7]. The precipitates volume fraction $f_{\mathrm{v}}$ is calculated using

$f_{\mathrm{v}}=\sum_{i} \frac{4}{3} \pi r_{\mathrm{i}}^{3} N_{\mathrm{i}}$

and the mean $\mathrm{Mg}$ solute concentration in the matrix $C_{\mathrm{Mg}}$ is given by

$C_{\mathrm{Mg}}=\frac{C_{0}-C_{\mathrm{p}} f_{\mathrm{v}}}{1-f_{\mathrm{v}}}$

where $C_{0}$ (wt.\%) is the initial $\mathrm{Mg}$ content in the alloy, assuming that the total amount of $\mathrm{Mg}$ will precipitate into fine $\mathrm{Mg}_{2} \mathrm{Si}$ precipitates.

\subsection{Yield strength prediction including the effect of natural aging}

The main contributions to strengthening in an age hardening aluminum alloy are summarized in this sub- 
section. It is assumed that the contribution of the grain size to the strengthening is negligible compared with the effect of the solute and small precipitates in heattreatable aluminum alloys. ${ }^{1}$ Indeed, assuming that the effect of the grain size on the yield strength $\sigma_{\mathrm{d}}$ can be expressed by Hall [9] and Petch [10] law, $\sigma_{\mathrm{d}}=k_{\mathrm{d}} d^{-1 / 2}$, with $k_{\mathrm{d}}$ a constant $\sim 0.04 \mathrm{MPa} \mathrm{m}^{-1 / 2}$ in aluminum [11-13] and a grain size $d$ of typically $10-50 \mu \mathrm{m}$ (respectively estimated grain sizes for the $\mathrm{WN}$ and the BM [3]), hence $\sigma_{\mathrm{d}}$ is $5-12 \mathrm{MPa}$ compared with the solute and precipitation contributions of 100-250 MPa (see Figs. 4 and 5).

- The solid solution contribution to the flow stress $\sigma_{\mathrm{ss}}$ is given by [14]

$$
\sigma_{\mathrm{ss}}=k_{(\mathrm{Mg}, \mathrm{Si})_{\mathrm{eq}}}\left(C_{\mathrm{Mg}}\right)^{2 / 3}+k_{\mathrm{Cu}}\left(C_{\mathrm{Cu}}\right)^{2 / 3}
$$

where $k_{(\mathrm{Mg}, \mathrm{Si})_{\text {eq }}}$ and $k_{\mathrm{Cu}}$ are two constants, and $C_{\mathrm{Cu}}$ is the $\mathrm{Cu}$ concentration in solid solution.

- The contribution from the precipitates to the flow stress $\sigma_{\text {preci }}$ is expressed as [15]

$\sigma_{\text {preci }}=\frac{M}{b}\left(2 k_{\Gamma} G b^{2}\right)^{-1 / 2} \frac{\bar{F}^{3 / 2}}{l}$

where $M$ is the Taylor factor, $G(\mathrm{~Pa})$ is the shear modulus, $b(\mathrm{~m})$ is the norm of the Burgers vector, $k_{\boldsymbol{\Gamma}}$ is a constant close to 0.5 and $l$ is the particle spacing in the glide plane given by

$l=r \sqrt{\frac{2 \pi}{3 f_{\mathrm{v}}}}$

and the average obstacle strength $\bar{F}$ is calculated using

$\bar{F}=\frac{\sum_{i} N_{i} F_{i}}{\sum_{i} N_{i}}$

where $F_{i}$ is the obstacle strength of the size class $i$. If the equivalent radius $r_{i}$ is smaller than an equivalent transition radius $r_{\text {trans }}$, the precipitates are sheared by the dislocations and $F_{i}=2 k_{\Gamma} G b^{2}\left(r / r_{\text {trans }}\right)$. If $r_{i}$ is larger than $r_{\text {trans }}$, the precipitates are bypassed by Orowan looping the dislocations and $F_{i}=2 k_{\Gamma} G b^{2}$. The transition radius is hence defined by the radius at which the precipitate/dislocation interaction mechanism changes, and it generally corresponds to the precipitates radius at maximum strength (i.e., the $\mathrm{BM}$ in the T6 state).

\footnotetext{
${ }^{1}$ The yield strength in the weld nugget of both welds is similar to its value in the TMAZ, see Fig. 5a and b. Considering that the grains in the weld nugget are much smaller than in the TMAZ [3] while in both regions the precipitates are fully dissolved, this result confirms the limited effect of the grain size on the yield strength. The effect of the grain size on strain hardening parameters requires additional extensions to the model which go out of the scope of the present study.
}

- The forest hardening contribution to the flow stress $\sigma_{\mathrm{pl}}$ is given by

$$
\sigma_{\mathrm{pl}}=M \alpha G b \sqrt{\rho}
$$

where $\rho$ is the dislocation density and $\alpha$ is a material dependent constant between 0.15 and 0.5 [16]. When estimating the yield strength, it will be assumed that $\sigma_{\mathrm{pl}}$ is much smaller than $\sigma_{\text {preci }}$.

Neglecting the initial dislocation density, the contributions to the yield strength $\sigma_{\mathrm{y}}$ are added up:

$\sigma_{\mathrm{y}}=\sigma_{0}+\sigma_{\mathrm{ss}}+\sigma_{\text {preci }}$

where $\sigma_{0}$ is the friction stress of pure aluminum $(\approx 10 \mathrm{MPa})$. The additive rule was advocated by Kocks et al. [17] as a result of the widely different pinning strengths of the various obstacles. Natural aging requires a specific additional treatment. It induces an increase in the yield strength due to the precipitation of GP zones, see [18]. Here, our interest lies only in the yield strength corresponding to the maximum possible amount of GP zones. A low supersaturation in $\mathrm{Mg}$ and $\mathrm{Cu}$ does not favor the precipitation of GP zones, and a certain amount of alloying elements $C_{\lim }$ (wt.\%) thus remains in solution during natural aging. The yield strength after natural aging $\sigma_{\mathrm{yNA}}$ can be calculated as

$$
\begin{aligned}
\sigma_{\mathrm{yNA}}= & \sigma_{\mathrm{y}}+K_{\mathrm{NA}} \sqrt{\frac{C_{\mathrm{Mg}}-C_{\mathrm{lim}}}{C_{0}-C_{\lim }}}-k_{(\mathrm{Mg}, \mathrm{Si})_{\mathrm{eq}}}\left(C_{\mathrm{Mg}}\right)^{2 / 3} \\
& +k_{(\mathrm{Mg}, \mathrm{Si})_{\mathrm{eq}}}\left(C_{\mathrm{lim}}\right)^{2 / 3}
\end{aligned}
$$

where $K_{\mathrm{NA}}(\mathrm{MPa})$ is a constant. The last two terms of expression (14) account for the loss of solid solution associated with GP zones formation, see the term $\sigma_{\mathrm{ss}}$ in Eq. (13).

\subsection{Strain hardening}

\subsubsection{KME model with Orowan loops storage around precipitates}

For pure metals, the Kocks-Mecking-Estrin (KME) model $[19,20]$ links the variation in the dislocation density $\rho$ with the local plastic shear strain $\gamma_{\mathrm{p}}$ :

$\frac{\mathrm{d} \rho}{\mathrm{d} \gamma_{\mathrm{p}}}=k_{1} \sqrt{\rho}-k_{2} \rho$

where $k_{1}$ and $k_{2}$ are proportionality constants. Using Eq. (12) and the definition of the Taylor factor $M$ (i.e., $\left.M=\sigma / \tau=\gamma_{\mathrm{p}} / \varepsilon_{\mathrm{p}}\right)$, one gets

$\left.\frac{\mathrm{d} \sigma_{\mathrm{f}}}{\mathrm{d} \varepsilon_{\mathrm{p}}}\right|_{\text {pure }}=\theta_{0}-\beta_{0}\left(\sigma_{\mathrm{f}}-\sigma_{\mathrm{y}}\right)$

where $\theta_{0}=\alpha G b M^{2} k_{1} / 2$ and $\beta_{0}=k_{2} M / 2$ are related to the dislocation storage rate and the dynamic recovery rate for pure materials, respectively. Experimental results from the literature [21-23] have shown that a linear relationship between the plastic slope and the flow stress holds also for aluminum alloys in solid solution. For alloys, the apparent 
'dislocation storage rate' and the apparent 'dynamic recovery rate' $\theta$ and $\beta$, respectively, will be defined, while $\theta_{0}$ and $\beta_{0}$ will be reserved for pure materials. The question now addressed is the dependence of $\theta$ and $\beta$ on the state of precipitation.

Several authors [23-25] have taken the storage of Orowan loops into account by introducing a new term inversely proportional to $l$ (see Eq. (10)), in the evolution of the dislocation density:

$\frac{\mathrm{d} \rho_{\mathrm{f}}}{\mathrm{d} \gamma_{\mathrm{p}}}=k_{1} \sqrt{\rho}+\frac{1}{b l}-k_{2} \rho$

leading to

$$
\begin{aligned}
\frac{\mathrm{d} \sigma_{\mathrm{f}}}{\mathrm{d} \varepsilon_{\mathrm{p}}} & =\frac{\mathrm{d} \sigma_{\mathrm{f}}}{\mathrm{d} \rho} \cdot \frac{\mathrm{d} \rho}{\mathrm{d} \gamma_{\mathrm{p}}} \cdot \frac{\mathrm{d} \gamma_{\mathrm{p}}}{\mathrm{d} \varepsilon_{\mathrm{p}}}=\frac{\alpha G b}{2 \sqrt{\rho}}\left(k_{1} \sqrt{\rho}+\frac{1}{b l}-k_{2} \rho\right) M \\
& =\theta_{0}+\frac{\alpha^{2} G^{2} b M^{3}}{2 l\left(\sigma_{\mathrm{f}}-\sigma_{\mathrm{y}}\right)}-\beta_{0}\left(\sigma_{\mathrm{f}}-\sigma_{\mathrm{y}}\right)
\end{aligned}
$$

For the sake of simplicity, the variation in $\left(\sigma_{\mathrm{f}}-\sigma_{\mathrm{y}}\right)$ between 0 and the saturation stress $\sigma_{\text {sat }}$ (value at which $\left.\left.\left(\mathrm{d} \sigma_{\mathrm{f}} / \mathrm{d} \varepsilon_{\mathrm{p}}\right)=0\right)\right)$ was assumed small enough to use a mean value of $\left(\sigma_{\mathrm{f}}-\sigma_{\mathrm{y}}\right)$ in the second term of (18), i.e., $\overline{\left(\sigma_{\mathrm{f}}-\sigma_{\mathrm{y}}\right)} \approx\left(\sigma_{\mathrm{sat}}-\sigma_{\mathrm{y}}\right) / 2=\theta /\left(2 \beta_{0}\right)$. The approximate linearity in $\left(\sigma_{\mathrm{f}}-\sigma_{\mathrm{y}}\right)$ of the work hardening rate is observed experimentally in Fig. 1, showing the evolution of the plastic slope as a function of the flow stress for various heat treatment times at $180{ }^{\circ} \mathrm{C}$ (see description later in Section 3 ). The assumption that $\theta$ is independent of the flow stress is thus an acceptable approximation that is reasonably valid for the heat-treated samples if one excludes the elastoplastic transition (see Fig. 1). Using (10), one gets, in the case of bypassed precipitates:

$\frac{\theta}{G}=\frac{\theta_{0}}{2 G}+\sqrt{\left(\frac{\theta_{0}}{2 G}\right)^{2}+\alpha^{2} M^{3} \beta_{0}\left(\frac{b}{r}\right) \sqrt{\frac{3 f_{\mathrm{v}}}{2 \pi}}}$

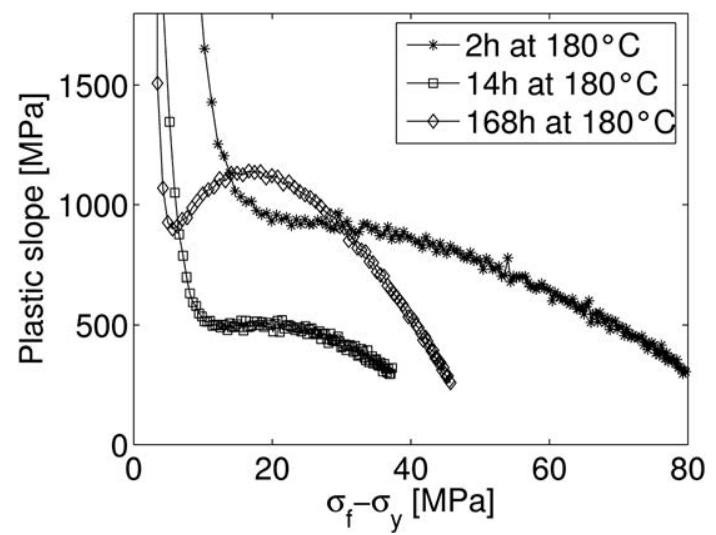

Fig. 1. Evolution of the plastic slope $\left(\mathrm{d} \sigma_{\mathrm{f}} / \mathrm{d} \varepsilon_{\mathrm{p}}\right)$ as a function of the flow stress $\sigma_{\mathrm{f}}$ for various heat treatment times at $180{ }^{\circ} \mathrm{C}$, starting for solutionized samples ( $\sigma_{\mathrm{y}}$ is the yield strength).

\subsubsection{Efficiency of Orowan loops storage}

In the classical approach to precipitation hardening, a precipitate, when bypassed, systematically stores a dislocation loop. However, it has been shown that, with increasing stress, the loop initially left by a bypassing process can become unstable, shear the precipitate and annihilate [26]. While this process occurs very easily for precipitate radii close to the shearing/bypassing transition, the critical stress for delayed shearing increases with increasing precipitate radius until it attains the radius corresponding to the loss of coherence $r_{\mathrm{cl}}$. For $r \geqslant r_{\mathrm{cl}}$, Orowan loops can no longer penetrate the non-coherent precipitates and are thus stable. An efficiency factor $\varphi$ for the storage of Orowan loops is introduced and defined as the proportion of Orowan loops that will not annihilate when the flow stress increases. When $r=r_{\text {trans }}$ and $\varphi=0$, Orowan loops just start forming and directly annihilate. When $r \geqslant r_{\mathrm{cl}}$ and $\varphi=1$, Orowan loops are efficiently stored. For the sake of simplicity, a linear variation will be assumed for $\varphi$ as a function of $r$. Hence, there will be no loop storage if the precipitates are sheared $\left(r<r_{\text {trans }}\right)$. When they are bypassed, the storage efficiency will grow from 0 to 1 between the two critical radii, if $r_{\text {trans }}<r<r_{\mathrm{cl}}$, then $\varphi=\left(r-r_{\text {trans }}\right) /\left(r_{\mathrm{cl}}-r_{\text {trans }}\right)$.

\subsubsection{Effect of supersaturated solution}

While the work hardening of stable solid solution has been extensively studied [27], the contribution of unstable solid solutions is still a matter of open debate. When a solid solution is supersaturated, its natural evolution is to precipitate. Precipitation from a supersaturated solid solution $\left(C_{\mathrm{Mg}}>C_{\mathrm{e}}\right)$ requires diffusion. During plastic flow, the movement of dislocations favors diffusion by creating vacancies [28] or by providing diffusion short circuits or by ballistic transport of a cloud of solute (i.e., non-random translation of atoms induced by the motion of dislocations). These processes can lead either to solute segregation at dislocation junctions which increases their strength, or even to precipitation [29]. Both effects, dynamic segregation and the so-called dynamic precipitation mechanism, lead to a hardening of the material proportional to the area spread by dislocations, i.e., proportional to plastic strain. Thus, this process leads to an apparent extra strain-hardening contribution. In order to describe this phenomenon, the dislocation storage parameter $\theta$ is increased by a quantity called $\theta_{\mathrm{dp}}$. Following Deschamps et al. [29], the contributions of dislocation storage and dynamic precipitation are added linearly. A linear relationship between the relative remaining excess solute and $\theta_{\mathrm{dp}}$ is proposed:

$\theta_{\mathrm{dp}}=k_{\theta_{\mathrm{dp}}}\left(\frac{C_{\mathrm{Mg}}-C_{\mathrm{e}}}{C_{0}-C_{\mathrm{e}}}\right)$

where $k_{\theta \mathrm{dp}}$ is an adjustable parameter.

\subsubsection{Effect of the yield strength on dynamic recovery}

The advantage of the Kocks-Mecking-Estrin formalism $[19,20,24]$ is that the parameters have a transparent physi- 
cal meaning so that the influence of microstructural features such as precipitation can be naturally introduced. The dynamic recovery rate $\beta_{0}$ is proportional to the annihilation distance between two dislocations of opposite sign $y_{\mathrm{a}}$ [27]. Dislocations annihilate when the interaction stress $\left(G b / y_{\mathrm{a}}\right)$ exceeds the yield strength. Hence, the dynamic recovery rate $\beta_{0}$ decreases with increasing yield stress (note that, among other things, this increase can be due to dynamic precipitation). The dynamic recovery rate $\beta$ is assumed to be inversely proportional to the initial yield strength $\sigma_{\mathrm{y}}$. By defining a reference minimum value $\beta_{\text {min }}$ corresponding to the maximum yield strength $\sigma_{\mathrm{y}}^{\max }$, the expression of $\beta_{0}$ becomes:

$\frac{1}{\beta_{\min }}-\frac{1}{\beta_{0}}=k_{\beta}\left(\frac{\sigma_{\mathrm{y}}^{\max }-\sigma_{\mathrm{y}}}{G}\right)$

where $k_{\beta}$ is a non-dimensional constant.

\subsubsection{Effect of the Orowan loops formation on dynamic recovery}

The presence of stable Orowan loops has an effect on the annihilation of mobile dislocations. The strong stress field associated with Orowan loops favors cross slip of the mobile dislocations coming nearby, leading to an increase in the critical distance of annihilation. This effect is presumably responsible for the 'spreading of plasticity' observed in alloys with bypassed precipitates [30]. Thus, a given mobile dislocation can annihilate with a dislocation of opposite sign coming from a glide plane further apart owing to the mechanical driving force provided by the nearby Orowan loop. One can express the annihilation distance between two dislocations of opposite sign $y_{\mathrm{a}}$ as

$y_{\mathrm{a}}=y_{0} p(0)+y_{\text {preci }}(1-p(0))$

where $y_{0}$ is the annihilation distance in the absence of Orowan loops, $y_{\text {preci }}$ is the annihilation distance between two dislocations of opposite sign meeting in the vicinity of a precipitate having stored an Orowan loop, on average, during the time for two moving dislocations to annihilate, $p(0)$ is the probability to encounter no precipitate before meeting a dislocation of opposite sign, i.e., the probability to have $y_{\mathrm{a}}=y_{0}$. It is easy to show that $p$ is given by a Poisson distribution involving the ratio $L_{0} / l$, where $L_{0}$ is the mean distance between dislocations and $l$ the distance between precipitates, hence $p(0)$ can be expressed as [3]:

$p(0)=\exp \left(-\sqrt{\frac{3}{2 \pi}} \frac{\sqrt{f_{\mathrm{v}}} L_{0} \varphi}{r}\right)$

where $L_{0}(m)$ is the mean distance between two moving dislocations of opposite sign. Note that the term $\varphi$ accounts for the stability of Orowan loops around the precipitates, as explained in Section 2.3.2. Now, $\beta$ can be directly written in terms of the critical annihilation distance, i.e. $\beta=2 y_{\mathrm{a}} / b$ [27], and (22) becomes

$\beta=\beta_{0} p(0)+\frac{2 y_{\text {preci }}}{b}(1-p(0))$

\subsubsection{Generalized KME model}

Eq. (19) can be modified (i) by taking the efficiency of dislocations storage $\varphi$ into account, i.e., by multiplying the $(1 / r)$ term by $\varphi$, (ii) by taking dynamic precipitation or dynamic segregation into account, i.e., by adding $\theta_{\mathrm{dp}}$ to the expression of $\theta$, (iii) by expressing the dynamic recovery rate using Eqs. (22) and (23), and (iv) by approximating the mean value of $\left(\sigma_{\mathrm{f}}-\sigma_{\mathrm{y}}\right)$ by $\theta /(2 \beta)$, which leads to expressions for the dislocation storage and dislocation recovery as a function of the precipitation characteristics:

$\frac{\theta}{G}=\frac{\theta_{0}+\theta_{\mathrm{dp}}}{2 G}+\sqrt{\left(\frac{\theta_{0}}{2 G}\right)^{2}+\alpha^{2} M^{3} \beta \varphi\left(\frac{b}{r}\right) \sqrt{\frac{3 f_{\mathrm{v}}}{2 \pi}}}$

$\beta=\beta_{0} \exp \left(-\sqrt{\frac{3}{2 \pi}} \frac{\sqrt{f_{\mathrm{v}}} L_{0} \varphi}{r}\right)+\frac{2 y_{\text {preci }}}{b}\left[1-\exp \left(-\sqrt{\frac{3}{2 \pi}} \frac{\sqrt{f_{\mathrm{v}}} L_{0} \varphi}{r}\right)\right]$

\section{Material and experimental procedure}

\subsection{Base material}

The material under investigation is a AA 6005A-T6 aluminum alloy with $0.81 \mathrm{wt} . \% \mathrm{Si}, 0.48 \mathrm{wt} . \% \mathrm{Mg}, 0.24 \mathrm{wt} . \%$ $\mathrm{Fe}$ and $0.11 \mathrm{wt} . \% \mathrm{Mn}$, in the form of 6-mm-thick extruded plates. Table 1 gives the BM tensile properties obtained with the loading direction oriented parallel to the extrusion direction and parallel to the transverse long direction. The mean values and standard deviation of these tensile properties are the result of five tensile tests in each loading directions. The fine precipitates were characterized by transmission electron microscopy (TEM) using the energy-filtered transmission electron microscopy (EFTEM) mode. The sample thickness reduction was obtained by electro-polishing in a $\mathrm{HNO}_{3}$ solution $\left(\mathrm{HNO}_{3} 30 \%\right.$ in volume in methanol at $-30{ }^{\circ} \mathrm{C}$ under $9 \mathrm{~V}$ ). The precipitates size distribution shown in Fig. 2 was generated by analyzing 620 different $\beta^{\prime \prime}$ precipitates end-on (i.e., precipitates with the long axis perpendicular to the plane of analysis) and 140 precipitates parallel to the plane (i.e., precipitates with the long axis parallel to the plane of analysis). The observation was made under the [001] zone axis, allowing the estimation of the mean equivalent radius $r$. The thickness of the samples was estimated using the electron energy loss spectroscopy (EELS) method in order to determine the number of precipitates per unit volume [8].

Table 1

Tensile properties of the aluminum alloy 6005A-T6 with the extrusion direction and the transverse long direction as loading direction

\begin{tabular}{lll}
\hline Direction of loading & Extrusion & Transverse long \\
\hline Yield strength at $0.2 \%, R_{\mathrm{p}}(\mathrm{MPa})$ & $265.6 \pm 2.2$ & $255.5 \pm 0.7$ \\
Tensile strength, $R_{\mathrm{m}}(\mathrm{MPa})$ & $287.8 \pm 1.2$ & $276.8 \pm 0.7$ \\
True strain at necking, $\varepsilon_{\mathrm{u}}$ & $0.086 \pm 0.001$ & $0.078 \pm 0.002$ \\
Dislocation storage rate, $\theta(\mathrm{MPa})$ & $918 \pm 29$ & $806 \pm 4$ \\
Recovery rate, $\beta$ & $11.8 \pm 0.4$ & $10.1 \pm 0.3$ \\
\hline
\end{tabular}




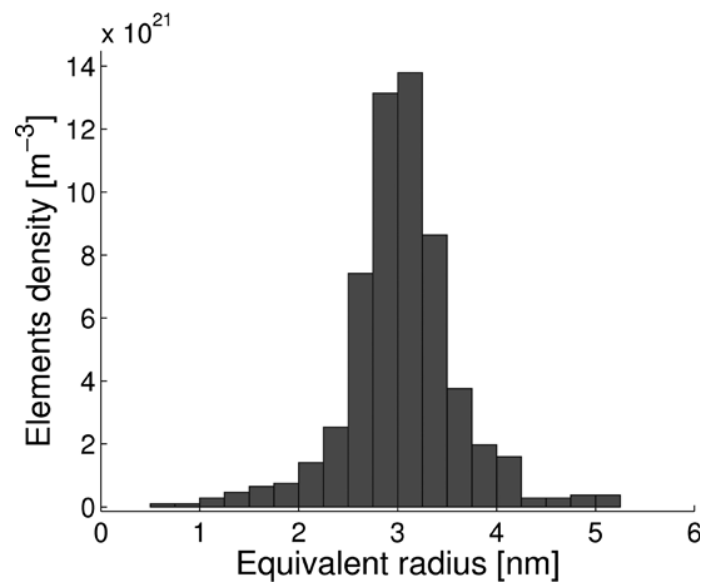

Fig. 2. Distribution of the $\beta^{\prime \prime}$ precipitates equivalent radius in the BM, considering that all the precipitates lengths are equal to the mean length.

\subsection{Isothermal heat treatments}

Isothermal heat treatments have been performed for various times at $180^{\circ} \mathrm{C}$ on samples of supersaturated solid solution naturally aged for 2 weeks, and at 300 and $350{ }^{\circ} \mathrm{C}$ on samples in the T6 state. Dog bone tensile specimens with a $12.5 \times 6 \mathrm{~mm}$ section were machined with the long axis parallel to the transverse long direction. The strainhardening parameters $\beta$ and $\theta$ associated with the KME model were extracted from the tensile curves using a least square linear fit on the $\mathrm{d} \sigma_{\mathrm{f}} / \mathrm{d} \varepsilon_{\mathrm{p}}$ vs $\left(\sigma_{\mathrm{f}}-\sigma_{\mathrm{y}}\right)$ plot (see Eq. (16)). Differential scanning calorimetry (DSC) measurements have also been performed on a solutionized sample in order to determine the $\beta^{\prime \prime}$ precipitation temperature.

\subsection{Welds}

The plates have been welded in the T6 state. Two welding conditions were extensively studied: (i) a 'hot weld' per- formed with an advancing speed of $200 \mathrm{~mm} \mathrm{~min}^{-1}$ and a rotational speed of $1000 \mathrm{rpm}$; and (ii) a 'cold weld' performed with the same rotational speed but with a five times larger advancing speed equal to $1000 \mathrm{~mm} \mathrm{~min}^{-1}$. The welding direction was the extrusion direction. During welding, thermocouples provided the thermal history at various distances from the weld centerline (see Ref. [31] for more details). The measured maximum temperature distributions are given in Fig. 5a and b.

Fine hardening precipitates were observed in the different regions of the weld by TEM. Micrographs extracted from the HAZ of the 'hot weld' and the 'cold weld' are shown in Fig. $3 a$ and $b$, respectively. The precipitates are larger in the HAZ of the 'hot weld' than in the same zone of the 'cold weld'. Vickers $1 \mathrm{~kg}$ hardness tests were performed on the transverse section of the welds at various distances from the weld centre, see the results on Fig. $5 \mathrm{a}$ and $\mathrm{b}$. The local tensile properties of the different zones were measured using micro-tensile specimens machined in each zone parallel to the weld axis; see details in Ref. [4].

\section{Results and discussion}

The parameters of the model were successively identified, the model was applied to isothermal heat treatments, and finally it was used to predict the local behavior in a FSW weld, which involves large temperature variations depending on the position with respect to the moving tool.

\subsection{Parameters identification}

The parameters required to apply the model described in Section 2 are gathered in Table 2 . The identification procedure consisted in the following steps. For more details, see also Ref. [3].
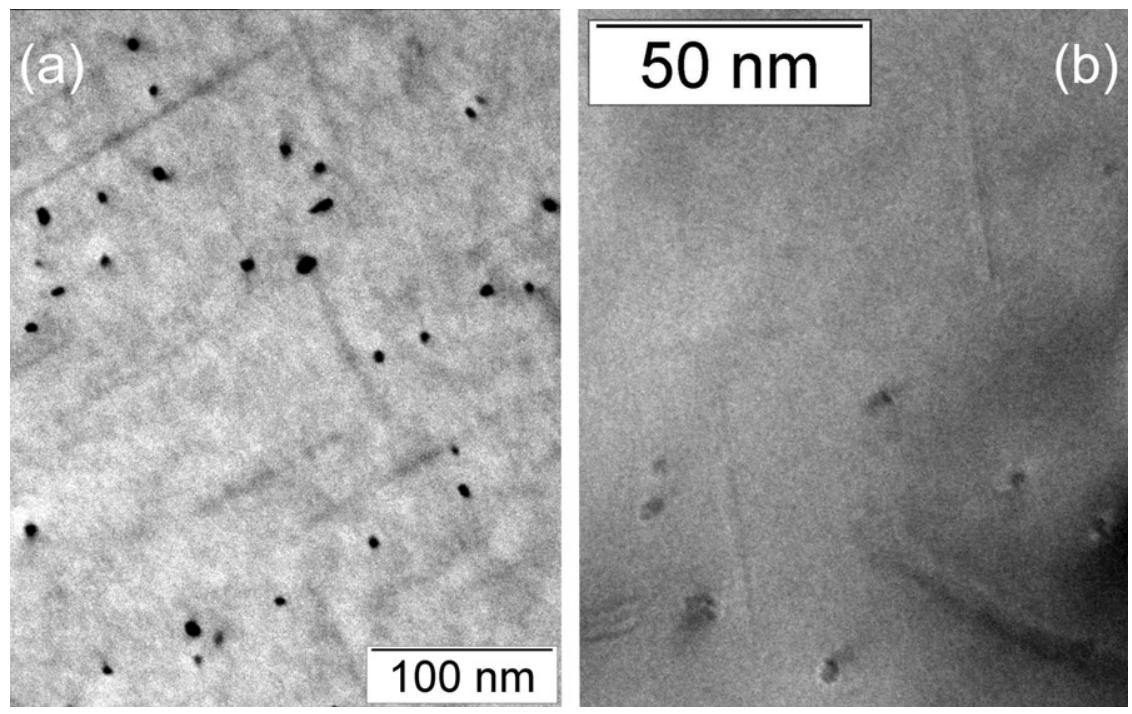

Fig. 3. Fine precipitation in the HAZ at the hardness minimum for two friction stir welds with a rotational speed of $1000 \mathrm{rpm}$. The hot weld (a) has an advancing speed of $200 \mathrm{~mm} \mathrm{~min}^{-1}$ and the cold weld (b) has an advancing speed of $1000 \mathrm{~mm} \mathrm{~min}^{-1}$. [100] $]_{\mathrm{Al}}$ zone axis. Note the difference in scales. 
Table 2

Summary of the parameters chosen for the application of the microstructural model, the yield strength model and the natural aging model to alloy AA 6005A ( $\mathrm{SS}=$ solid solution, $\mathrm{BM}=$ base material, $\mathrm{NA}=$ natural aging)

\begin{tabular}{|c|c|c|c|}
\hline Parameters & Significance & Value & Origin \\
\hline$r$ for $\mathrm{BM}$ & BM equivalent radius & Fig. 2 & TEM on BM \\
\hline$C_{0}$ & $\mathrm{Mg}$ content of alloy 1 & 0.48 wt. $\%$ & $\mathrm{Mg}$ content in alloy AA $6005 \mathrm{~A}$ \\
\hline$C_{\mathrm{p}}$ & $\mathrm{Mg}$ content in $\mathrm{Mg}_{2} \mathrm{Si}$ & 63.4 wt. $\%$ & [5] \\
\hline$A_{0}$ & Parameter of the energy barrier for nucleation & $18.6 \mathrm{~kJ} \mathrm{~mol}^{-1}$ & DSC and $\approx[6-8]$ \\
\hline$V_{\mathrm{m}}$ & Molar volume of $\mathrm{Mg}_{2} \mathrm{Si}$ & $3.95 \times 10^{-5} \mathrm{~m}^{3} \mathrm{~mol}^{-1}$ & {$[5]-[-1$} \\
\hline$C_{\mathrm{e} 0}$ & Pre-exponential term to $C_{\mathrm{e}}$ & 290 wt. $\%$ & [8] \\
\hline$Q_{\mathrm{e}}$ & Apparent solvus boundary enthalpy & $41 \mathrm{~kJ} \mathrm{~mol}^{-1}$ & [8] \\
\hline$D_{0}$ & Pre-exponential term to the diffusion coefficient & $10^{-4} \mathrm{~m}^{2} \mathrm{~s}^{-1}$ & Optimized on heat treatment results \\
\hline$Q_{\mathrm{d}}$ & Activation energy for diffusion & $130 \mathrm{~kJ} \mathrm{~mol}^{-1}$ & {$[5-8]$} \\
\hline$j_{0}$ & Pre-exponential term to the nucleation rate $j$ & $3 \cdot 10^{37} \#\left(\mathrm{~m}^{3} \mathrm{~s}\right)^{-1}$ & Optimized on heat treatment results \\
\hline$\gamma$ & Precipitate/matrix interface energy & $0.26 \mathrm{~J} \mathrm{~m}^{-2}$ & Optimized $+[6-8]$ \\
\hline$M$ & Taylor factor & 2 & Textured alloy [39] \\
\hline G & Shear modulus & $2.7 \cdot 10^{10} \mathrm{GPa}$ & {$[6-8]$} \\
\hline$b$ & Magnitude of Burger's vector & $2.84 \cdot 10^{-10} \mathrm{~m}$ & {$[6-8]$} \\
\hline$\sigma_{0}$ & Yield strength of pure aluminum & $10 \mathrm{MPa}$ & [6-8] \\
\hline$k_{\mathrm{Cu}}$ & Constant for effect of $\mathrm{Cu}$ in $\mathrm{SS}$ content on $\sigma_{\mathrm{ss}}$ & $46.4 \mathrm{MPa}$ wt. $\%{ }^{2 / 3}$ & {$[6-8]$} \\
\hline$K(\mathrm{Mg}, \mathrm{Si})_{\mathrm{eq}}$ & Constant for effect of $\mathrm{Mg}$ and $\mathrm{Si}$ in SS content on $\sigma_{\mathrm{ss}}$ & $39.7 \mathrm{MPa}$ wt. $\%{ }^{2 / 3}$ & $\sigma_{\mathrm{y}}$ for a solution heat-treated sample $[3]$ \\
\hline$r_{\text {trans }}$ & Transition radius & $3.04 \mathrm{~nm}$ & $\begin{array}{l}\text { Mean radius of T6 state precipitate size } \\
\text { distribution (Fig. 2) }\end{array}$ \\
\hline$k_{\Gamma}$ & Line tension constant & 0.45 & $\sigma_{\mathrm{y}}$ in T6 state (Table 1 ) \\
\hline$C_{\lim }$ & Limit $C_{\mathrm{Mg}}$ for NA & 0.39 wt. $\%$ & DSC, model and welds, see Annex B \\
\hline$K_{\mathrm{NA}}$ & Constant for NA model & $58.1 \mathrm{MPa}$ & $\begin{array}{l}\text { Eq. (14) and } \sigma_{y} \text { in for a solution heat-treated } \\
\text { sample before and after NA [3] }\end{array}$ \\
\hline$\theta_{0}$ & $\theta$ if no dynamic precipitation and no Orowan loops & $600 \mathrm{MPa}$ & $\theta$ minimum of Fig. $4 \mathrm{~b}$ \\
\hline$\beta_{\min }$ & $\beta$ when $\sigma_{\mathrm{y}}$ is minimum & 7.5 & $\beta$ minimum of Fig. $4 \mathrm{c}$ \\
\hline$k_{\theta \mathrm{dp}}$ & Constant for the dynamic precipitation effect on $\theta$ & $1270 \mathrm{MPa}$ & $\begin{array}{l}\theta \text { for a solution heat-treated sample [3] and the } \\
\text { BM at T6 state [4] }\end{array}$ \\
\hline$k_{\beta}$ & Constant linking $\sigma_{\mathrm{y}}$ to $\beta$ & 9.3 & $\begin{array}{l}\beta \text { for a solution heat-treated sample [3] and the } \\
\text { BM at T6 state [4] }\end{array}$ \\
\hline$r_{\mathrm{cl}}$ & Radius of loss of coherency & $25 \mathrm{~nm}$ & $r$ of $\theta$ and $\beta$ transition in Fig. $4 \mathrm{~b}$ and $\mathrm{c}$ \\
\hline$L_{0}$ & Distance between two moving dislocations of opposite sign & $100 \mathrm{~nm}$ & $L_{0} \approx \alpha G b M \frac{2 \beta_{\min }}{\theta_{0}}$ \\
\hline$\alpha$ & Constant linking the dislocation density to the shear stress & 0.21 & Optimized on $\theta$ of heat-treated samples for $r$ \\
\hline$y_{\text {preci }}$ & $\begin{array}{l}\text { Annihilation distance when at least one precipitate is } \\
\text { between two dislocations of opposite sign }\end{array}$ & $22 \mathrm{~nm}$ & $\begin{array}{l}>r_{\text {trans }} \\
\text { Optimized on } \beta \text { of heat-treated samples for } r \\
>r_{\text {trans }}\end{array}$ \\
\hline
\end{tabular}

- Fig. 2 shows the BM precipitate size distribution. The mean equivalent radius is equal to $3.0 \mathrm{~nm}$ with a standard deviation of $0.6 \mathrm{~nm}$.

- The radius of transition $r_{\text {trans }}$ from precipitates shearing to bypassing almost corresponds to the mean radius associated with the T6 state (see Fig. 2); i.e., $r_{\text {trans }} \approx 3.0 \mathrm{~nm}$.

- The parameter $A_{0}$ of Eq. (1) was found equal to $18.6 \mathrm{~kJ} \mathrm{~mol}^{-1}$ in order to maximize the nucleation rate at $260{ }^{\circ} \mathrm{C}$, which is the temperature corresponding to the peak of $\beta^{\prime \prime}$ precipitation in the DSC measurements on the solution heat-treated sample [3].

- The parameters $D_{0}, j_{0}$ and $\gamma$ were identified from the yield strength values measured on heat-treated samples at $180^{\circ} \mathrm{C}$. The value $D_{0}=10^{-4} \mathrm{~m}^{2} \mathrm{~s}^{-1}$ agrees with the value found by Van Horn [32] but differs from the result $\left(D_{0}=2 \cdot 2 \cdot 10^{-4} \mathrm{~m}^{2} \mathrm{~s}^{-1}\right)$ given by Myhr et al. [5-8]. The value $\gamma=0.26 \mathrm{~J} \mathrm{~m}^{-2}$ corresponds to the value given by Myhr et al. [8]. This value thus constitutes a compromise between $\gamma=0.02 \mathrm{~J} \mathrm{~m}^{-2}$ when all precipitates are coherent and $\gamma=0.6 \mathrm{~J} \mathrm{~m}^{-2}$ when all precipitates are incoher- ent. Here, a single mean value of $\gamma$ is used to encompass both coherent $\beta^{\prime \prime}$ precipitates and larger semi-coherent $\beta^{\prime}$ precipitates. The value $j_{0}=3 \times 10^{37} \#\left(\mathrm{~m}^{3} \mathrm{~s}\right)^{-1}$ is slightly higher than $j_{0}=3.07 \times 10^{36} \#\left(\mathrm{~m}^{3} \mathrm{~s}\right)^{-1}$ given by Myhr et al. [8].

- A large value of $C_{\lim }=0.39 \mathrm{wt} . \%$ is chosen based on the weld simulation results of Fig. 5 and previous DSC results, which showed only GP zones formation at the HAZ minimum hardness and closer to the WN [4].

- The dislocation storage parameter $\theta$ is only slightly different from its value in pure $\mathrm{Al}, \theta_{0}$, when all the alloying elements have precipitated in the form of coherent precipitates that are sheared by dislocations [22]. Hence, a value of the dislocation storage parameter for pure $\mathrm{Al}$, $\theta=\theta_{0}=600 \mathrm{MPa}$, is used in the BM.

- The radius of loss of coherency $r_{\mathrm{cl}}$ is identified from the tensile test on the heat-treated samples (see Fig. 4), which is described in the next section. Both $\theta$ and $\beta$ reach a maximum for $r \approx 25 \mathrm{~nm}$, thus providing a value for $r_{\mathrm{cl}}$ in the expected range for the radius of loss of coherency [33]. 


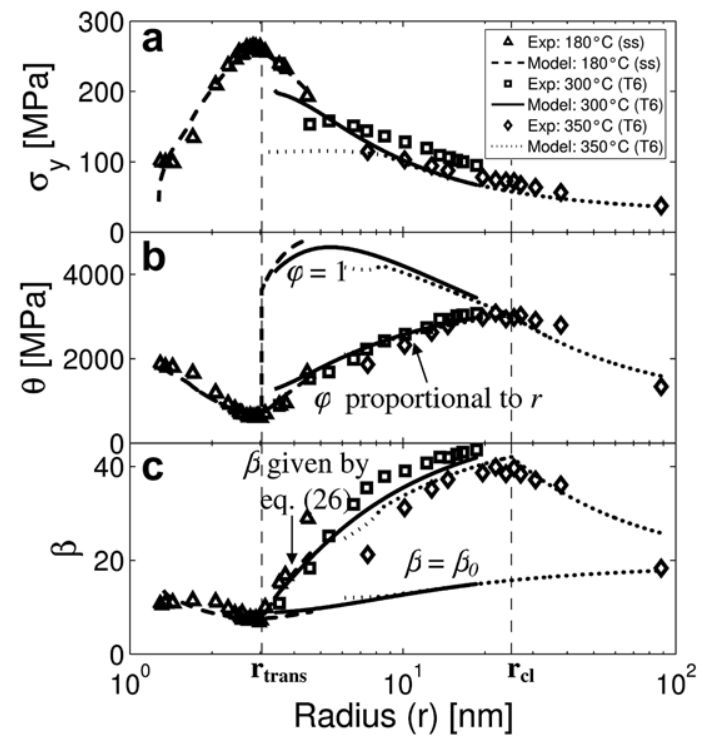

Fig. 4. Evolution as a function of the mean equivalent radius $r$ (predicted by the microstructure evolution model) of the predicted and measured (a) yield strength $\sigma_{\mathrm{y}}$, (b) dislocation storage rate $\theta$ and (c) dynamic recovery rate $\beta$. The samples were solution heat treated and aged at $180^{\circ} \mathrm{C}$ or heat treated at $300{ }^{\circ} \mathrm{C}$ and $350^{\circ} \mathrm{C}$ from the T6 state. $\varphi$ is the efficiency of dislocation storage.

- The dislocation spacing $L_{0}$ can be calculated from $L_{0}=1 / \sqrt{\rho}=M \alpha G b / \sigma_{\mathrm{p} 1 / 0}$.

- The forest hardening contribution can be estimated as $\sigma_{\mathrm{p} 1 / 0} \approx \theta_{0} / 2 \beta_{0}$, giving $L_{0}=100 \mathrm{~nm}$.

- The value of $y_{\text {preci }}$ was identified from the experimental values of $\beta$ obtained on heat-treated samples. The best fit is obtained for $y_{\text {preci }}=22 \mathrm{~nm}$. This value is much higher than the critical distance $\left(y_{0} \approx 1 \mathrm{~nm}\right)$ for dislocation annihilation when no Orowan loops are present [27]. Furthermore, $y_{\text {preci }}$ is in the range of $\beta^{\prime}$ precipitate lengths under over-aging conditions, in agreement with the simple qualitative argument that the dislocations de-localize on a distance of the order of the precipitates length.

\subsection{Models applied to isothermal heat treatments}

Fig. 4 shows the evolution of the predicted yield strength $\sigma_{\mathrm{y}}$, dislocation storage parameter $\theta$ and dynamic recovery rate $\beta$ as a function of the equivalent radius compared with the experimental results with the transverse long direction as loading direction. Fig. 4 does not present a systematic analysis of the scatter, but it would most certainly be similar to the BM tensile properties scatter presented in Table 1. Even though the data in Fig. 4 have been used for the model identification, the good agreement between the computed and experimental curves show that the model is rich enough to reproduce the different variations. These results deserve some more comments.

\subsubsection{Under-aged conditions (i.e., $r<r_{\text {trans }}, \varphi=0$ )}

The potential of the model to capture the decrease in the dislocation storage parameter $\theta$ with increasing precipitate size and hence decreasing solid solution concentration confirms that accounting for the effect of dynamic precipitation or dynamic segregation through a linear relationship with the excess solute concentration seems good enough. The evolution of the dynamic recovery rate $\beta$ is qualitatively well reproduced, confirming the need for taking into account the influence of the yield strength on the dynamic recovery rate.

\subsubsection{Over-aged conditions (i.e., $r_{\text {trans }}<r<r_{c l}$ )}

As expected for over-aging, the yield strength decreases with increasing radius when $r>r_{\text {trans. }}$. Within a classical KME approach, the parameter $\theta$ would exhibit an 'instantaneous' jump when $r=r_{\text {trans }}$ and then be inversely proportional to $r$ (see Eq. (19) and the corresponding curve $\varphi=1$ in Fig. 4b). The experimentally observed slower increase in the dislocation storage parameter $\theta$ is correctly captured by the modified model proposed here, owing to the introduction of the efficiency of the storage of Orowan loops around coherent precipitates. Fig. 4c shows that the experimental increase in the dynamic recovery rate $\beta$ is much larger than the increase associated only with $\beta_{0}$ (effect of the yield strength on $\beta$ ), again supporting the need to account for the influence of the presence of Orowan loops on recovery.

\subsubsection{Massive over-aging (i.e., $r>r_{c l}, \varphi=1$ )}

The yield strength keeps decreasing monotonously. This experimentally observed effect is well captured by the model. Both $\theta$ and $\beta$, after reaching their maximum for $r=r_{\mathrm{cl}}$, start decaying for massive over-aging. This decrease is due to the stable storage of Orowan loops around incoherent precipitates.

\subsection{Application to friction stir welds}

Class models are well suited to describe precipitation evolution in non-isothermal treatments. The experimentally measured thermal cycles during welding [31] are given as inputs for the precipitation model which, with the values of the various parameters identified above, delivers the values of the precipitate radius and volume fraction. These last data are then used as inputs for the mechanical model. Fig. 5a and $b$ shows the variation in the volume fraction of precipitates, precipitate radius and flow properties (hardness, yield strength, strain-hardening parameters $\theta$ and $\beta$, and ultimate tensile strength) as a function of the position along a transverse section of the weld for both (a) the hot weld and (b) the cold weld.

The experimental distribution of both the precipitates characteristics and tensile properties are reasonably well reproduced by the model, especially considering that the predictions of the flow properties are based on the predicted radius and volume fraction which adds an extra source of error. The various regions of the welds present the following microstructure and tensile properties evolution. 

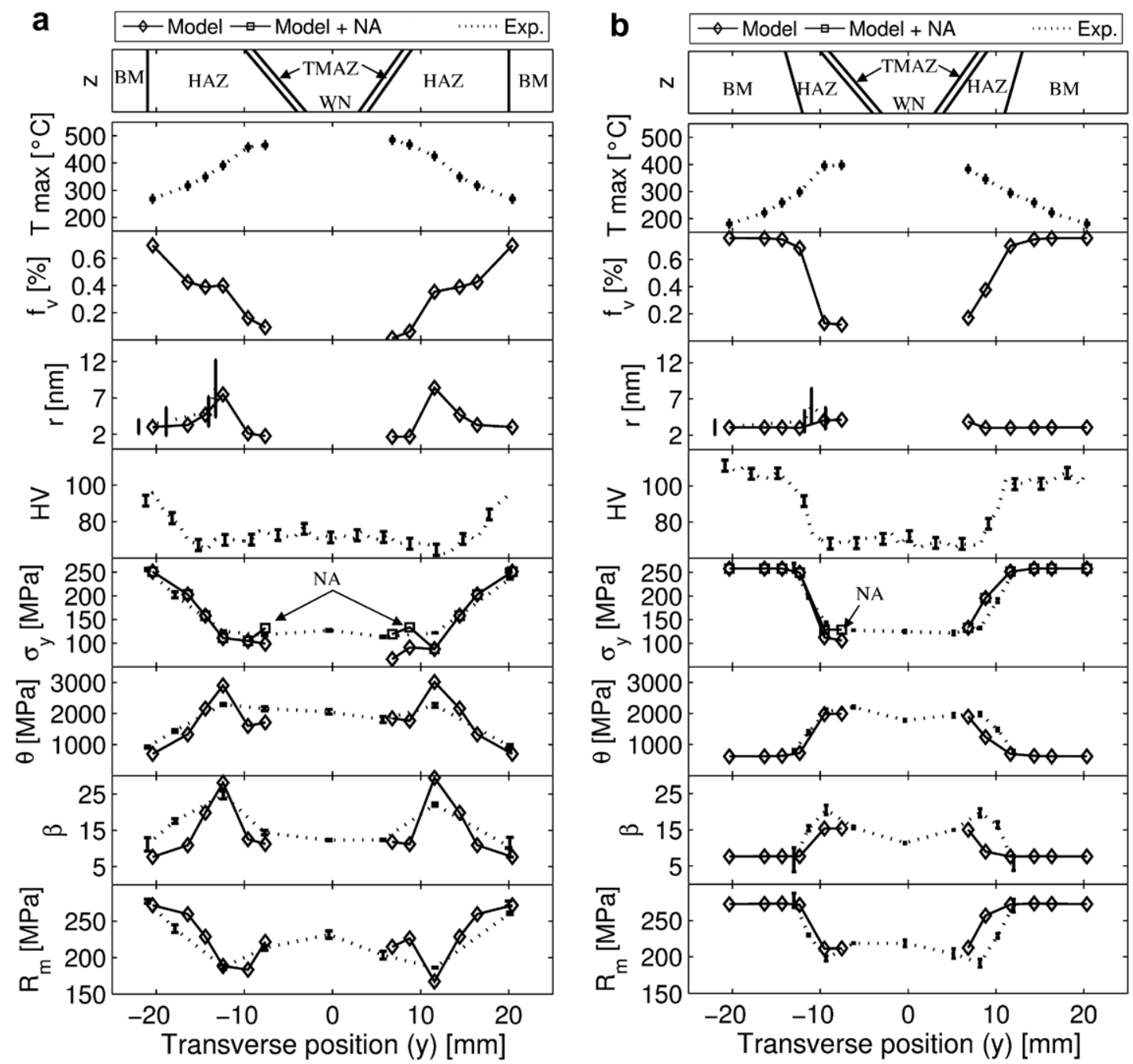

Fig. 5. From top to bottom for (a) the hot weld and (b) the cold weld ( $z=$ thickness direction, $y=$ transverse position) shapes of the weld zones. See Ref. [31] for the maximum temperature distribution $T_{\max }$ (typical error of $7^{\circ} \mathrm{C}$ indicated by error bars). Comparison between the experimental results (from [4]) and predictions (where available) at mid-thickness of the precipitates volume fraction $f_{\mathrm{v}}$, the precipitates mean equivalent radius $r$, the Vickers $1 \mathrm{~kg}$ hardness HV (typical error of $4 \mathrm{HV}$ indicated by error bars), the yield strength $\sigma_{\mathrm{y}}$, the dislocation storage parameter $\theta$, the dynamic recovery rate $\beta$ and the ultimate tensile strength $R_{\mathrm{m}} \cdot y=0$ is the joint line and $y<0$ is the advancing side (the rotation of the tool is in the same direction as the advancing velocity). NA = natural aging. Error bars indicate the standard deviation from the mean values.

\subsubsection{Heat affected zone (HAZ)}

The HAZ is characterized by a maximum temperature ranging between $300^{\circ} \mathrm{C}$ and $450{ }^{\circ} \mathrm{C}$. Up to a maximum temperature of $400^{\circ} \mathrm{C}$, the mean precipitate radius increases, as observed by the TEM micrographs analysis reported in Fig. 5a and b, and the precipitates volume fraction $f_{\mathrm{v}}$ decreases towards the weld axis. As a consequence, the yield strength decreases. Natural aging has little effect on the yield strength for medium to high $f_{\mathrm{v}}$ owing to the high value of $C_{\text {lim. }}$. In the HAZ, some Orowan loops start being permanently stored since $r>r_{\text {trans }}$ and dynamic precipitation is permitted. Those two effects add up to increase the level of the dislocation storage parameter $\theta$. The lower yield strength and the Orowan loops formation are the cause of the drastic increase in the dynamic recovery rate $\beta$ observed experimentally with the tensile tests performed on the specimens machined within the HAZ. For a maxi- mum temperature between $400{ }^{\circ} \mathrm{C}$ and $450{ }^{\circ} \mathrm{C}$, preferential dissolution of initial precipitates is observed in the hot weld.

\subsubsection{Weld nugget}

The WN was not modeled, as no temperature measurements were available for that region of the weld, but the tensile test results can be qualitatively interpreted based on the predictions of the model. In the WN, most of the elements are in solid solution (i.e., very low $f_{\mathrm{v}}$ ). Hence, the yield strength is low just after welding but increases by natural aging up to a level similar to that observed in the HAZ. Dynamic precipitation favors a high value of the dislocation storage parameter $\theta$ which is only slightly lower than in the HAZ. On the contrary, the dynamic recovery rate $\beta$ presents a low value in the $\mathrm{WN}$ which is only slightly larger than in the BM, thanks to a lower yield 
strength in the WN. The higher $R_{\mathrm{m}}$ in the WN compared with the HAZ can be understood by the strain-hardening model. Indeed, $\theta$ is high and $\beta$ is relatively low in the weld center, while both $\theta$ and $\beta$ are maximum in the HAZ. Hence, it is the dynamic recovery and, in particular, the ability of dislocations to delocalize owing to the presence of the Orowan loops which seems to govern the difference in $R_{\mathrm{m}}$ between the WN and the HAZ.

Two differences are significant when comparing the hot weld (Fig. 5a), with an advancing speed of $200 \mathrm{~mm} / \mathrm{min}$, and the cold weld (Fig. 5b), with an advancing speed of $1000 \mathrm{~mm} / \mathrm{min}$.

For similar maximum temperature, the precipitates equivalent radius in the HAZ is larger in the hot weld compared with the cold weld (see also Fig. 3). This is a consequence of the lower heating and cooling rates in hot welds, which favors coarsening. Indeed, the maximum temperature in the low yield strength region is about $400{ }^{\circ} \mathrm{C}$ for both welds, but the cooling rate in the cold weld is equal to $42{ }^{\circ} \mathrm{C} \mathrm{s}^{-1}$ between $300{ }^{\circ} \mathrm{C}$ and $200{ }^{\circ} \mathrm{C}$, while it is equal to only $10{ }^{\circ} \mathrm{C} \mathrm{s}^{-1}$ in the hot weld. This difference results from the different advancing speeds.

The precipitates volume fraction in the HAZ is larger in the hot weld compared with the cold weld. This prediction is supported by post-welding heat treatment experiments performed on the welds, as described elsewhere [4]. Indeed, the hardness recovery after a post-welding heat treatment is lower in the hot weld compared with the cold weld. The reason for this difference in the precipitate volume fraction is the sudden change between precipitates' coarsening and their massive dissolution, which are two antagonistic effects on the evolution of the volume fraction. No plateau in $f_{\mathrm{v}}$ is observed in the cold weld $\left(1000 \mathrm{~mm} \mathrm{~min}^{-1}\right)$, again owing to the higher cooling rates, favoring dissolution rather than coarsening, which has a lower kinetic.

The experimentally observed difference in the local tensile properties between the hot (Fig. 5a) and cold weld (Fig. 5b) can be understood directly based on the aforementioned differences in the precipitation evolution.

The HAZ is wider in the hot weld compared with the cold weld. This can be concluded from the hardness measurements presented in Fig. 5a and b and is a consequence of the lower maximum temperatures in the cold weld (see top of Fig. 5b), compared with the hot weld (see top of Fig. 5a). Indeed, even though there is a competition between dissolution and coarsening, the drop of hardness and yield strength is associated mainly with the start of dissolution which is essentially governed by the maximum temperature.

The yield strength is slightly lower in the HAZ of the hot weld compared with the cold weld. The lower solid solution concentration in the HAZ of the hot weld (i.e., higher $f_{\mathrm{v}}$ ) does not favor natural aging in the HAZ. The difference in the dynamic recovery rates of the HAZ in the two welds is very large. Hence, the lower yield strength of the HAZ of the hot weld compared with the HAZ of the cold weld has a second order effect on the global behavior difference between the hot and cold welds. The strain hardening governs the global behavior of the welds.

The dislocation storage rate $\theta$ and the dynamic recovery rate $\beta$ are larger in the HAZ of the hot weld compared with the same zone in the cold weld, leading to a lower value of the ultimate tensile strength $R_{\mathrm{m}}$ in the HAZ in the hot weld. This important conclusion resulting from the experimental measurements can now be explained by the model as being due to the larger precipitate radius in the hot weld favoring the stability of Orowan loops ( $\varphi$ increases with $r)$. The effect is slightly exaggerated by the model, as it underestimates the mean precipitate radius in the cold weld.

\section{Conclusions}

An integrated three steps model for predicting the (i) precipitates evolution, (ii) yield strength, and (iii) strain hardening, relating the thermal history and the chemistry to the end use plastic properties, was developed, identified and validated through application on isothermal heat treatments and friction stir welded joints of a AA 6005A-T6 alloy.

A specific effort was devoted to building a new strainhardening model which modifies the classical Kocks-Mecking-Estrin formalism by including the effects of dynamic precipitation on the dislocation storage rate, the effect of yield strength on the dynamic recovery rate and the effect of the instability of Orowan loops for small precipitates coherent with the matrix on both the dislocation storage rate and the dynamic recovery rate.

The main variations in the tensile properties of the welds are explained by differences in the strain-hardening behaviors which control the strength and resistance to plastic localization. In particular, the lower strength in the HAZ compared with the $\mathrm{WN}$ is due to different dynamic recovery rates for similar dislocation storage rates. The strength of the HAZ is lower in the hot weld compared with the cold weld owing to differences in the dynamic recovery caused by variations in precipitate radius and volume fraction.

A fully integrated approach of the welding optimization towards enhanced performances in terms of forming operations or structural integrity requires additional ingredients in the chain of models. First, a model for the process, coupling the material flow and the thermal analysis, is required at the beginning of the chain (see recent studies in the literature [3,34-36]). Secondly, at the end of the chain the present microstructure-based strength and strain-hardening model could be coupled to a micromechanical model for the damage evolution in order to analyze the risks of fracture during forming operations or within a structure under loading, see recent development for $6 \mathrm{xxx}$ aluminum alloys $[3,37,38]$.

\section{Acknowledgements}

A. Simar acknowledges the financial support of FRIA Belgium. Authors are grateful to C. Gallais for providing 
the basis computer program for the microstructure evolution modeling. Brian Wirth is acknowledged for his valuable comments. Part of this research has also been carried out under the interuniversity attraction poles P6/ 24, funded by the Belgian Science Policy.

\section{Appendix A}

The ultimate tensile strength $R_{\mathrm{m}}(\mathrm{MPa})$ and the strain at necking $\varepsilon_{\mathrm{u}}$ can be deduced from the predictions of the dislocation storage parameter $\theta$ and the dynamic recovery rate $\beta$ by applying the Considere's necking condition which writes

$\left.\frac{\mathrm{d} \sigma_{\mathrm{f}}}{\mathrm{d} \varepsilon_{\mathrm{p}}}\right|_{\text {necking }}=\sigma_{\mathrm{f}}=\theta-\beta\left(\sigma_{\mathrm{f}}-\sigma_{\mathrm{y}}\right)$

Since at necking $\sigma_{\mathrm{f}}=\sigma_{\mathrm{u}}$, the true stress at necking, one finds:

$\sigma_{\mathrm{u}}=\frac{\theta+\beta \sigma_{\mathrm{y}}}{1+\beta}$

By integrating Eq. (A1), one obtains the expression of the true strain as a function of the true stress, which is known as the Voce law, giving an expression for the strain at necking $\varepsilon_{\mathrm{u}}$ as

$\varepsilon_{\mathrm{u}}=\frac{-1}{\beta} \ln \left(1-\frac{\beta}{\theta}\left(\sigma_{\mathrm{u}}-\sigma_{\mathrm{y}}\right)\right)$

The engineering ultimate tensile strength is given by $R_{\mathrm{m}}=\sigma_{\mathrm{u}} \exp \left(-\varepsilon_{\mathrm{u}}\right)$.

\section{References}

[1] Thomas WM, Nicholas ED, Needham JC, Murch MG, Templesmith P, Dawes CJ. GB Patent Application No. 9125978.8, December 1991; US Patent No. 5460317, October 1995.

[2] Mishra RS, Ma ZY. Mat Sci Eng R 2005;50:1-78.

[3] Simar A. Ph.D. Thesis (2006), Université catholique de Louvain (UCL), Belgium.

[4] Simar A, Bréchet Y, de Meester B, Denquin A, Pardoen T. Microstructure, local and global mechanical properties of friction stir welds in aluminum alloy 6005A-T6. Met Mater Trans A; in press

[5] Myhr OR, Grong O. Acta Mater 2000;48:1605-15.

[6] Myhr OR, Grong O, Andersen SJ. Acta Mater 2001;49:65-75.

[7] Myhr OR, Grong O, Klokkehaug S, Fjaer HG. In: Bhadeshia HKDH, editor. Mathematical modelling of weld phenomena, vol. 6. London: Maney Publishing; 2002.
[8] Myhr OR, Grong O, Fjaer HG, Marioara CD. Acta Mater 2004;52:4997-5008.

[9] Hall EO. Proc Phys Soc 1951;64:747.

[10] Petch NJ. J Iron Steel Inst 1953;174:25.

[11] Fujita H, Tabata T. Acta Metall 1973;21:355-65.

[12] Hansen N. Acta Metall 1977;25:863-9.

[13] Nes E, Holmedal B, Evangelista E, Marthinsen K. Mater Sci Eng A 2005;410-411:178-82.

[14] Haasen P. In: Nabarro FRN, editor. Dislocations in solids, vol. 4. Amsterdam: North-Holland; 1979. p. 155.

[15] Gerold V. Precipitation hardening. In: Dislocations in solids. Amsterdam: North-Holland Publishing Company; 1979. p. 234.

[16] Ashby MF, Strengthening methods in crystals, in: Kelly A, Nicholson RB, editors, Elsevier, Amsterdam, p. 137.

[17] Kocks UF, Ashby MF, Argon AS. Progress Mat Sci 1975;19.

[18] Esmaeili S, Lloyd DJ, Poole WJ. Acta Mater 2003;51:3467-81.

[19] Mecking H, Kocks UF. Acta Metall 1981;29:1865-75.

[20] Estrin Y, Mecking H. Acta Metall 1984;32(1):57-80.

[21] Chu D, Morris JW. Acta Mater 1996;44(7):2599-610.

[22] Esmaeili S, Cheng LM, Deschamps A, Lloyd DJ, Poole WJ. Mat Sci Eng A 2001;319-321:461-5.

[23] Cheng LM, Poole WJ, Embury JD, Lloyd DJ. Metall Mater Trans A 2003;34A:2473-81.

[24] Estrin Y, Krausz AS, Krausz K, editors, Academic Press, San Diego, 1996, p. 69-106.

[25] Poole WJ, Lloyd DJ. In: Nie JF, Morton AJ, Muddle BC, editors. Proceeding of the 9th International Conference Aluminium Alloys. Inst. Mater. Eng. Australasia Ltd.; 2004.

[26] Brechet Y, Louchet F. Acta Metall 1989;37(9):2469-73.

[27] Deschamps A, Brechet Y, Necker CJ, Saimoto S, Embury JD. Mater Sci Eng A 1996;207:143-52.

[28] Estrin Y, Lücke K. Scripta Met 1985;19(2):221-3.

[29] Deschamps A, Nieuwczas M, Bley F, Brechet Y, Embury JD, Le Sinq L, Livet F, Simon JP. Philo Mag A 1999;79(10):2485-504.

[30] Dubost B, Sainfort P, traités Mat. metal. M240, les Techniques de l'ingénieur, October 1991.

[31] Simar A, Pardoen T, de Meester B. Sci Technol Weld Joining 2007;12(4).

[32] Van Horn KR, Aluminium properties, physical metallurgy and phase diagrams, vol. 1; 1967

[33] Iwamura S, Miura Y. Acta Mater 2004;52:591-600.

[34] Heurtier P, Jones MJ, Desrayaud C, Driver JH, Montheillet F, Allehaud D. J Mat Processing Tech 2006;171:348-57.

[35] Schmidt HNB, Dickerson TL, Hattel JH. Acta Mater 2006;54:1199-209.

[36] Williams SW, Colegrove PA, Shercliff H, Prangnell P, Robson J, Withers P, et al. In: Proceedings of the 6th International Symposium FSW, Saint-Sauveur, Canada; October 2005, TWI.

[37] Gallais C, Simar A, Fabègue D, Denquin A, Lapasset G, de Meester B, Berchet Y, Pardoen T. Met Mater Trans A 2007.

[38] Lassance D, Fabrègue D, Delannay F, Pardoen T. Progress Mater Sci 2007;52(1):62-129.

[39] A. Deschamps, Ph.D. Thesis, INPG Grenoble, France; 1997. 